\title{
Synthesis, Characterization, Absorption and Fastness Properties of Novel Monoazo Dyes Derived from 1-Phenyl-3-amino-4-(2-thiazolilazo)pyrazol-5-one
}

\author{
Fatma Erol ${ }^{\odot *, a}$ \\ ${ }^{a}$ Technical Sciences Vocational School, Gazi University, Ostim-06374, Ankara, Turkey
}

\begin{abstract}
Monosubstitute thiazolyl amines were diazotized in acetic acid, coupled to 1-phenyl3-aminopyrazol-5-one (1a-1c) and acetylated to obtain the 2a-2c dyes. The dyes were characterized by elemental analysis and spectroscopic (Fourier transform infrared (FTIR), nuclear magnetic resonance (NMR), ultraviolet (UV)) methods. The effects on the visible absorption spectra of the substituents present, solvents, $\mathrm{pH}$, concentration and temperature were investigated in detail. Tautomerism of the dyes were investigated by spectroscopic methods. Fastness properties of dyes were studied using the standard method for the assessment of color fastness of textile.
\end{abstract}

Keywords: hetarylazopyrazolone, substituent effect, tautomerism, fastness

\section{Introduction}

Azo dyes are most widely used to dye polyester due to versatility. Among these azo dyes, heterocyclic moieties, e.g., pyrazolone, indole, pyrimidine, imidazole, pyridone, quinolone, coumarin, etc., provide higher tinctorial strength and brighter texture as compared to dyes based on phenylic components. ${ }^{1-5}$

Hetarylazo dyes based on heterocyclic diazo and coupling components have been attracted the attention of scientists in recent years. ${ }^{6-12}$ Among these, the hetarylazopyrazolone dyes have high fluorescence, high quantum yield, superior photostability in the visible region, excellent fastness properties, ${ }^{13-16}$ tautomeric structures ${ }^{6,7,10,17}$ in addition to their bathochromic effects in the absorption spectra. ${ }^{6,710,17}$ The absorption and emission properties of the pyrazolones can be tuned according to the properties of the solvent, especially where electron-withdrawing and electron-donating substituents are attached at the 1, 3 and 4-positions of pyrazolone ring. These pyrazolones have shown numerous properties such as non-linear optical chromophores, optical brighteners, as well as being used in solar cells, ${ }^{18,19}$ laser printing systems, laser optical recording systems. ${ }^{12,20}$ Some of the pyrazolones were found as biologically active and acted as medicine. ${ }^{21,22}$

2-Aminothiazoles are widely used in the dye industry as a coupling and diazo components in addition to their important pharmacological and biological activities. ${ }^{23,24}$ Hetarylazo disperse dyes obtained from the coupling of

*e-mail: fnuralin@gazi.edu.tr heterocyclic diazo components have shown better rubbing, light and washing fastnesses properties than carbocyclic components. . $5-27^{2}$

Herein we report the synthesis and derivatization of 3-amino-1-phenyl-4-(2-thiazolilazo)pyrazol-5-one (dyes 1a-1c) and 3-acetamido-1-phenyl-4-(2-thiazolilazo) pyrazol-5-one (dyes 2a-2c) (Scheme 1). Synthesized dyes were characterized by elemental analysis, Fourier transform infrared (FTIR) and ${ }^{1} \mathrm{H}$ nuclear magnetic resonance (NMR) spectroscopies. The influence of substituent, solvents, $\mathrm{pH}$, concentration, and temperature on their visible absorption spectra were also investigated. Tautomerism of the synthesized dyes were investigated using spectroscopic methods. Fastness properties of dyes were obtained by standard method that has been used for the color fastness of textiles. This study also contributes to the physical, spectral and tautomeric properties of hetarylazopyrazolones. In addition, the effect of oxochrome $-\mathrm{NH}_{2}$ (dyes 1a-1c) and chromophor $-\mathrm{NH}-\mathrm{CO}-\mathrm{CH}_{3}$ (dyes 2a-2c) substituents at the 3 -position of pyrazolone ring, electron withdrawing $-\mathrm{NO}_{2}$ and electron donating $-\mathrm{CH}_{3}$ substituents on the thiazol ring were also investigated on the color fastness (washing, rubbing, light fastness and increase/diversify the color range) of the novel hetarylazopyrazolone dyes (Scheme 1).

\section{Experimental}

\section{General}

Reagents/reactants were either bought from SigmaAldrich Chemical Company (St. Louis, USA) or Merck 


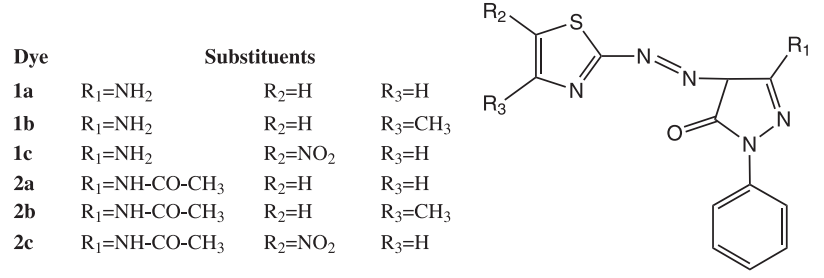

Scheme 1. The molecule formulas of the dyes.

Chemical Company (Darmstadt, Germany) and used without further purification. The solvents used were of highperformance liquid chromatography (HPLC) grade. FTIR spectra were determined on a $\mathrm{KBr}$ disc using a MATTSON 1000 spectrophotometer Fourier Transform-Infrared (FT-IR). 'H NMR spectra were recorded on a BrukerSpectrospin Avance DTX 400 Ultra-Shield in deuterated dimethyl sulfoxide (DMSO- $d_{6}$ ) using trimethylsilane (TMS) as an internal standard; chemical shifts $(\delta)$ are given in ppm. Ultraviolet (UV) absorption spectra were recorded in various solvents, i.e., dimethylsulfoxide (DMSO, Merck, Darmstadt, Germany), dimethylformamide (DMF, Merck, Darmstadt, Germany), acetonitrile (SigmaAldrich, St. Louis, USA), methanol (Merck, Darmstadt, Germany), acetic acid (Sigma-Aldrich, St. Louis, USA) and chloroform (Merck, Darmstadt, Germany) using a ATI (UK) UNICAM UV2-100 Ultraviolet-Visible (UV-Vis) spectrophotometer. Change in $\lambda_{\max }(\mathrm{nm})$ was investigated when $0.1 \mathrm{~mL}$ piperidine (Merck, Darmstadt, Germany) and $0.1 \mathrm{~mL}\left(0.1 \mathrm{~mol} \mathrm{~L}^{-1}\right)$ trifluoroacetic acid (TFAA, Sigma-
Aldrich, St. Louis, USA) were added to $1 \mathrm{~mL}$ dye solutions in chloroform (Merck, Darmstadt, Germany). Similarly, $0.1 \mathrm{~mL}$ potassiumhydroxide (KOH, Sigma-Aldrich, St. Louis, USA, $0.1 \mathrm{~mol} \mathrm{~L}^{-1}$ ) or $0.1 \mathrm{~mL}$ hydrochloric acid (HCI, Sigma-Aldrich, St. Louis, USA, $0.1 \mathrm{~mol} \mathrm{~L}^{-1}$ ) was added to $1 \mathrm{~mL}$ dye solutions in methanol (Merck, Darmstadt, Germany). In addition, the $\lambda_{\max }$ of dyes were investigated at variable temperatures and concentrations in DMF (Merck, Darmstadt, Germany). Melting points were measured with a Gallenkamp capillary melting apparatus. The light, washing and the rubbing fastness tests were performed using xenon arc lamp method (ATLAS, West Yorkshire, UK), washing method (ATLAS, West Yorkshire, UK) and crock meter method (ATLAS, West Yorkshire, UK, staining of cotton rubbing fabric), respectively.

\section{Synthesis}

Hetarylazopyrazolone dyes (1a-1c) were prepared by the coupling 3-amino-1-phenyl-2-pyrazolin-5-one with diazotized 2-thiazolyl amines in acetic acid. The dyes 2a-2c (Scheme 1) were synthesized by acetylation of (1a-1c) dyes (Scheme 2). Table 1 shows physical properties of the dyes.

Synthesis of 1-phenyl-3-amino-4-(2-thiazolilazo)pyrazol5-one (1a)

2-Aminothiazole (Merck, Darmstadt, Germany, 4 mmol,<smiles>[R]c1csc(N=NC2C(=O)N(c3ccccc3)N=C2NC(C)=O)n1</smiles>

Scheme 2. The synthetic route of the dyes.

Table 1. Physical properties and characterization data of the synthesized dyes

\begin{tabular}{|c|c|c|c|c|c|c|c|c|c|c|c|c|c|}
\hline \multirow{2}{*}{ Dye } & \multirow{2}{*}{$\begin{array}{l}\text { Molecular } \\
\text { formula }\end{array}$} & \multirow{2}{*}{ Appearance } & \multirow{2}{*}{ Crystallization solvent } & \multirow{2}{*}{$\begin{array}{c}\text { Melting } \\
\text { point } /{ }^{\circ} \mathrm{C}\end{array}$} & \multirow{2}{*}{$\begin{array}{c}\text { Yield / } \\
\%\end{array}$} & \multicolumn{2}{|c|}{$\mathrm{C} / \%$} & \multicolumn{2}{|c|}{$\mathrm{H} / \%$} & \multicolumn{2}{|c|}{$\mathrm{N} / \%$} & \multicolumn{2}{|c|}{$\mathrm{S} / \%$} \\
\hline & & & & & & Calcd. & Found & Calcd. & Found & Calcd. & Found & Calcd. & Found \\
\hline $1 \mathrm{a}$ & $\mathrm{C}_{12} \mathrm{H}_{10} \mathrm{ON}_{6} \mathrm{~S}$ & brown & acetic acid/water & $218-220$ & 87 & 50.35 & 50.06 & 3.49 & 3.56 & 29.37 & 29.14 & 11.18 & 11.34 \\
\hline $1 \mathrm{~b}$ & $\mathrm{C}_{13} \mathrm{H}_{12} \mathrm{ON}_{6} \mathrm{~S}$ & brown & acetic acid/water & $240-242$ & 82 & 52.03 & 51.67 & 4.00 & 4.01 & 28.00 & 27.72 & 10.66 & 10.41 \\
\hline $1 \mathrm{c}$ & $\mathrm{C}_{12} \mathrm{H}_{9} \mathrm{O}_{3} \mathrm{~N}_{7} \mathrm{~S}$ & dark brown & chloroform/hexane & $262-263$ & 61 & 43.50 & 43.12 & 2.71 & 2.96 & 29.60 & 30.05 & 9.66 & 9.33 \\
\hline $2 \mathbf{a}$ & $\mathrm{C}_{14} \mathrm{H}_{12} \mathrm{O}_{2} \mathrm{~N}_{6} \mathrm{~S}$ & dark brown & toluene & $244-245$ & 75 & 51.22 & 50.97 & 3.65 & 3.53 & 25.60 & 24.85 & 9.75 & 8.93 \\
\hline $2 b$ & $\mathrm{C}_{15} \mathrm{H}_{14} \mathrm{O}_{2} \mathrm{~N}_{6} \mathrm{~S}$ & dark brown & chloroform/hexane & $250-252$ & 77 & 52.63 & 52.11 & 4.09 & 3.92 & 24.56 & 23.89 & 9.35 & 8.78 \\
\hline $2 \mathrm{c}$ & $\mathrm{C}_{14} \mathrm{H}_{11} \mathrm{O}_{4} \mathrm{~N}_{7} \mathrm{~S}$ & dark brown & toluene & $273-275$ & 75 & 45.04 & 45.48 & 2.94 & 2.61 & 26.27 & 25.87 & 8.57 & 8.12 \\
\hline
\end{tabular}


$404 \mathrm{mg}$ ) was dissolved in icy acetic acid $(5 \mathrm{~mL})$ and cooled to $0{ }^{\circ} \mathrm{C}$ in ice-salt bath. Nitrosyl sulfuric acid prepared with dissolving sodium nitrite (Merck, Darmstadt, Germany, $4 \mathrm{mmol}, 304 \mathrm{mg}$ ) in sulfuric acid (Sigma-Aldrich, St. Louis, USA, $5.5 \mathrm{~mL}$ ) was dropwise added into the heterocyclic amine during $30 \mathrm{~min}$ at $0{ }^{\circ} \mathrm{C}$. The mixture was stirred while cold for additional $2 \mathrm{~h}$. 1-Phenyl-3-aminopyrazol-5-one (Merck, Darmstadt, Germany, $4 \mathrm{mmol}, 697 \mathrm{mg}$ ) and $\mathrm{KOH}$ $(500 \mathrm{mg})$ were dissolved in water $(10 \mathrm{~mL})$ and cooled to $0{ }^{\circ} \mathrm{C}$. The prepared diazonium solution was added into the reaction mixture in $30 \mathrm{~min}$ and stirred for additional $2 \mathrm{~h}$ at $0{ }^{\circ} \mathrm{C}$. The product was precipitated out by adding dilute $\mathrm{KOH}$, filtered, washed with water and air dried. Recrystallization was performed in acetic acid:water mixture (v/v) to obtain the pure brown compound with $87 \%$ yield $(3.48 \mathrm{mmol}$, $995 \mathrm{mg}$ ), mp $218-220{ }^{\circ} \mathrm{C}$.

The dyes $\mathbf{1 b}$ and $\mathbf{1 c}$ were synthesized similarly to synthesis of dye 1a. Dye 1b was obtained with $82 \%$ yield $(3.28 \mathrm{mmol}, 984 \mathrm{mg}), \mathrm{mp} 240-242{ }^{\circ} \mathrm{C}$. Dye 1c was synthesized with $61 \%$ yield $(2.44 \mathrm{mmol}, 808 \mathrm{mg})$, mp 262-263 ${ }^{\circ} \mathrm{C}$.

Synthesis of 1-phenyl-3-acetamido-4-(2-thiazolilazo) pyrazol-5-one (2a)

1-Phenyl-3-amino-4-(2-thiazolilazo)pyrazol-5-one (1a) ( $2 \mathrm{mmol}, 572 \mathrm{mg}$ ) and acetic anhydride (Sigma-Aldrich, St. Louis, USA, $2 \mathrm{mmol}, 8 \mathrm{~mL}$ ) mixture was refluxed for $5 \mathrm{~h}^{28}$ The mixture was added into water $(200 \mathrm{~mL})$ to precipitate the product at room temperature and boiled for $10 \mathrm{~min}$. The product was filtered, washed with water and air dried. Recrystallization was performed in toluene (Merck, Darmstadt, Germany) to give the pure dark brown compound with $75 \%$ yield (1.5 mmol, $492 \mathrm{mg}$ ), mp $244-245^{\circ} \mathrm{C}$.

The dyes $\mathbf{2 b}$ and $\mathbf{2 c}$ were synthesized similarly to synthesis of dye 1a. Dye $\mathbf{2 b}$ was obtained with $77 \%$ yield (1.5 mmol, $527 \mathrm{mg}$ ), $\mathrm{mp} 250-252^{\circ} \mathrm{C}$. Dye $2 \mathbf{c}$ was synthesized with $75 \%$ yield $(1.5 \mathrm{mmol}, 560 \mathrm{mg}), \mathrm{mp} 273-275^{\circ} \mathrm{C}$.

\section{Dyeing method}

Polyester fabric was dyed according to the carrier dyeing method in the laboratory. The carrier swells the polyester fibers, increasing interstitial space to accept more dye molecules into the polymer system.

Dyeing of polyester fabric $(4 \times 10 \mathrm{~cm}, 2.5 \mathrm{~g})$ was performed at a liquor ratio of 100:1 and 2\% owf (on weight fabric). Carrier (diphenyl, Sigma-Aldrich, St. Louis, USA, $0.5 \mathrm{~g}$ ), dispersing agent (Sera Sperse M-15, DyeStar, Singapore, $0.25 \mathrm{~g})$, ammonium sulfate $\left(\left(\mathrm{NH}_{4}\right)_{2} \mathrm{SO}_{4}\right.$, Merck, Darmstadt, Germany, $0.25 \mathrm{~g}$ ) and acetic acid $(\mathrm{pH} 5)$ were added into the bath $(250 \mathrm{~mL})$ at $40{ }^{\circ} \mathrm{C}$. After $15 \mathrm{~min}$, dye $(0.05 \mathrm{~g})$ was added into the bath. Once the fabric was introduced into the bath, the temperature was slowly raised up to $90^{\circ} \mathrm{C}$. After $60 \mathrm{~min}$, the dye bath was cooled down to $40^{\circ} \mathrm{C}$ (Figure 1).

The dyed fabric was taken out of the bath and thoroughly washed with cold then hot distilled water. Reduction cleaning was done with $1 \%$ soup solution at boiling temperature for $15 \mathrm{~min}$ to improve the wash fastness. The fabric was again rinsed with distilled water and dried in the air.

\section{Assessment of fastness}

The light, washing and rubbing fastness tests were carried out according to the ISO $105-\mathrm{B} 04,{ }^{29}$ ISO $105-\mathrm{C} 06^{30}$ and ISO $105-\mathrm{X} 12^{31}$ (staining of cotton rubbing fabric). The light fastness tests were determined using the international blue scale (1-8), the rubbing and washing fastness tests were determined using the international grey scale (1-5), where the maximum was ranked the best while least was the inferior. ${ }^{32,33}$

\section{Results and Discussion}

\section{Structure}

FTIR $\left(\mathrm{KBr}, v\right.$, in $\left.\mathrm{cm}^{-1}\right)$ spectra of all dyes showed a carbonyl band at $1664-1677 \mathrm{~cm}^{-1}, \mathrm{NH}_{2}$ and $-\mathrm{NH}$ of hydrazo form band at $3397-3467 \mathrm{~cm}^{-1}$. These values suggest that all dyes are in keto-hydrazo form $\left(\mathrm{T}_{2}\right)$ in solid state. . $3,6,8,8,12,17,34$

The ${ }^{1} \mathrm{H}$ NMR ( $\delta$ in ppm) spectra of all the synthesized dyes were measured in DMSO- $d_{6}$. The dyes showed broad singlet peaks at 5.75-6.60 ppm $\left(-\mathrm{NH}_{2}: \mathbf{1 a}-\mathbf{1 c}\right)$ and

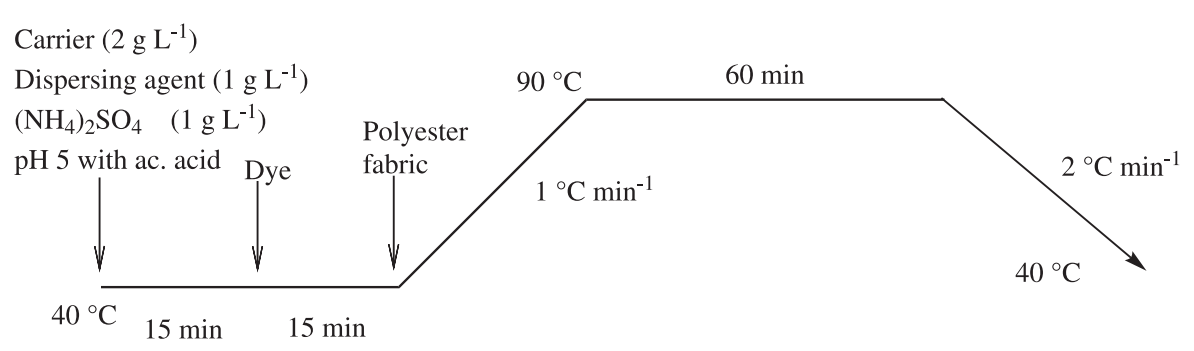

Figure 1. Disperse dyeing procedure used for polyester. 
7.80-9.20 ppm (acetamido NH: 2a-2c), two doublets at 7.70-8.40 ppm (thiazole ring: 1a and 2a), singlet at 8.00-8.50 ppm (monosubstitute thiazole ring: $\mathbf{1 b}, \mathbf{1 c}, \mathbf{2 b}$ and 2c), singlet, double and multiplets at $6.75-8.00 \mathrm{ppm}$ (phenyl ring), a singlet at 2.75-2.80 ppm (thiazole $-\mathrm{CH}_{3}$ : 1b and 2b), a singlet at 3.10-3.80 ppm (acetamido $\mathrm{CH}_{3}$ : 2a-2c) and a singlet at $12.30-14.40 \mathrm{ppm}$ (hydrazo $-\mathrm{NH}$ protons: all dyes, except $\mathbf{2 a}$ and $\mathbf{2 b}$ ). The ${ }^{1} \mathrm{H}$ NMR spectra of dyes $\mathbf{2} \mathbf{a}$ and $\mathbf{2} \mathbf{b}$ showed neither $-\mathrm{NH}$ proton of hydrazo nor the $-\mathrm{OH}$ proton of enol tautomer. These results suggest that dyes 1a-1c and $\mathbf{2 c}$ may be in keto-hydrazo form $\left(\mathrm{T}_{2}\right)$ while 2a and $\mathbf{2 b}$ may be in an anionic form $\left(\mathrm{A}_{1}\right)$ in DMSO. $8,17,34$

FTIR and ${ }^{1} \mathrm{H}$ NMR spectral data of the dyes are shown in Table 2.

\section{Tautomerism}

Tautomerism is important not only for chemical properties, but also for different properties as colors and fastness properties. For this reason, the possible tautomeric forms of examined dyes were evaluated in detail. The possible tautomeric forms of the dyes $\left(\mathrm{T}_{1}-\mathrm{T}_{6}\right)$ are shown in Scheme 3.

The synthesized new dyes may exist in five possible tautomeric forms, i.e., keto-azo $\left(\mathrm{T}_{1}\right.$ and $\left.\mathrm{T}_{5}\right)$, keto-hydrazo $\left(\mathrm{T}_{2}\right.$ and $\left.\mathrm{T}_{4}\right)$ and enol-azo $\left(\mathrm{T}_{3}\right)$. According to the calculation results in the literature, ${ }^{17,35-40}$ the most stable tautomeric form is keto-hydrazo form $\left(\mathrm{T}_{2}\right)$ for hetarylazopyrazolone dyes. This conclusion may occur from the intramolecular $\mathrm{O}-\mathrm{H}$ bond.

Table 2. Spectral data for the dyes

\section{Solvent effects}

The absorption spectra of the synthesized dyes were measured in a range of $10^{-6}-10^{-8} \mathrm{~mol} \mathrm{~L}^{-1}$ in various solvents. The dielectric constants of the solvents were found in the following order: chloroform $\left(\mathrm{CHCI}_{3}\right)>$ acetic acid $>$ methanol $>$ acetonitrile $>$ DMF $>$ DMSO. Experimental $\lambda_{\max }$ values of dyes are listed in Table 3 .

The absorption spectra of $\mathbf{1 a}, \mathbf{1 b}, \mathbf{2} \mathbf{a}$ and $\mathbf{2 b}$ showed only one $\lambda_{\max }$ in all solvents. Additionally, $\mathbf{1 a}$ and $\mathbf{1 b}$ showed a shoulder at shorter wavelength in methanol, DMF and methanol, DMF, DMSO while 2a and 2b showed it at shorter wavelength in chloroform only. These shoulders indicate the interchange of tautomeric or anionic forms in these solvents. These results as well as ${ }^{1} \mathrm{H}$ NMR data suggests that $\mathbf{1 a}$ and $\mathbf{1 b}$ may be in keto-hydrazo $\left(\mathrm{T}_{2}\right)$ and anionic form $\left(\mathrm{A}_{1}\right)$ in methanol, DMSO and DMF while 2a and $\mathbf{2 b}$ may be in the keto-hydrazo $\left(\mathrm{T}_{4}\right)$ and keto-azo form $\left(\mathrm{T}_{1}\right.$ or $\left.\mathrm{T}_{5}\right)$ in chloroform while in the remaining solvents, these dyes may exist in only one tautomeric or ionic form.

Dyes 1c and 2c showed two maxima in chloroform, methanol, acetonitrile, DMF and DMSO which may have arisen either from the mixture of tautomeric forms or a mixture of a tautomeric and anionic form. ${ }^{7,35}{ }^{1} \mathrm{H}$ NMR data of these dyes suggest that $1 \mathbf{c}$ and $2 \mathrm{c}$ may be in the keto-hydrazo $\left(\mathrm{T}_{2}\right)$ and anionic form $\left(\mathrm{A}_{1}\right)$ or may be in the keto-hydrazo $\left(\mathrm{T}_{4}\right)$ and one of keto-azo forms $\left(\mathrm{T}_{1}\right.$ or $\left.\mathrm{T}_{5}\right)$ in all solvents, except acetic acid. All the synthesized dyes have one maximum that may belong to the cationic form in acetic acid (one of $\mathrm{C}_{1}-\mathrm{C}_{6}$, Scheme 4).

\begin{tabular}{|c|c|c|}
\hline Dye & ${ }^{1} \mathrm{H}$ NMR $\left(400 \mathrm{MHz}\right.$, DMSO- $\left.d_{6}\right) \delta / \mathrm{ppm}$ & $\operatorname{FTIR}(\mathrm{KBr}) \vee / \mathrm{cm}^{-1}$ \\
\hline $1 \mathbf{a}$ & $\begin{array}{c}6.65\left(\mathrm{~s}, 2 \mathrm{H}, \mathrm{NH}_{2}\right), 7.00(\mathrm{~s}, 1 \mathrm{H}, \mathrm{ph}), 7.25(\mathrm{~m}, 2 \mathrm{H}, \mathrm{ph}) \\
7.50(\mathrm{~m}, 2 \mathrm{H}, \mathrm{ph}), 7.75(\mathrm{~d}, 1 \mathrm{H}, J 8.0 \mathrm{~Hz}, \mathrm{th}) \\
8.05(\mathrm{~d}, 1 \mathrm{H}, J 8.0 \mathrm{~Hz}, \mathrm{th}), 12.30(\mathrm{~s}, 1 \mathrm{H}, \mathrm{hyd} \mathrm{NH})\end{array}$ & $\begin{array}{c}3397(\text { hyd NH}), 3307,3234\left(\mathrm{NH}_{2}\right), 3184,3082(\mathrm{Ar} \mathrm{CH}), \\
1664(\mathrm{k} \mathrm{C}=\mathrm{O}), 1592,1503(\mathrm{C}=\mathrm{N}, \mathrm{C}=\mathrm{C})\end{array}$ \\
\hline 1b & $\begin{array}{c}2.75\left(\mathrm{~s}, 3 \mathrm{H}, \text { th } \mathrm{CH}_{3}\right), 6.50\left(\mathrm{~s}, 2 \mathrm{H}, \mathrm{NH}_{2}\right), 6.75(\mathrm{~s}, 1 \mathrm{H}, \mathrm{ph}) \\
7.00(\mathrm{~m}, 1 \mathrm{H}, \mathrm{ph}), 7.25(\mathrm{~m}, 1 \mathrm{H}, \mathrm{ph}), 7.50(\mathrm{~m}, 2 \mathrm{H}, \mathrm{ph}) \\
8.10(\mathrm{~s}, 1 \mathrm{H}, \mathrm{th}), 13.90(\mathrm{~s}, 1 \mathrm{H}, \text { hyd NH})\end{array}$ & $\begin{array}{c}3423\left(\text { hyd NH), } 3319,3249\left(\mathrm{NH}_{2}\right), 3185(\mathrm{Ar} \mathrm{C}-\mathrm{H}), 2922\right. \\
2830(\mathrm{Al} \mathrm{C}-\mathrm{H}), 1669(\mathrm{k} \mathrm{C}=\mathrm{O}), 1599,1545,1499(\mathrm{C}=\mathrm{N}, \mathrm{C}=\mathrm{C})\end{array}$ \\
\hline 1c & $\begin{array}{c}5.75\left(\mathrm{~s}, 2 \mathrm{H}, \mathrm{NH}_{2}\right), 7.00(\mathrm{~m}, 1 \mathrm{H}, \mathrm{ph}), 7.25(\mathrm{~m}, 2 \mathrm{H}, \mathrm{ph}) \\
7.75(\mathrm{~s}, 1 \mathrm{H}, \mathrm{th}), 8.45(\mathrm{~s}, 1 \mathrm{H}, \mathrm{ph}), 8.55(\mathrm{~s}, 1 \mathrm{H}, \mathrm{ph}) \\
13.75(\mathrm{~s}, 1 \mathrm{H}, \text { hyd NH})\end{array}$ & $\begin{array}{c}3467(\text { hyd } \mathrm{NH}), 3352,3275\left(\mathrm{NH}_{2}\right), 3133,3070(\mathrm{Ar} \mathrm{CH}) \\
1676(\mathrm{k} \mathrm{C}=\mathrm{O}), 1592,1548,1471(\mathrm{C}=\mathrm{N}, \mathrm{C}=\mathrm{C})\end{array}$ \\
\hline $2 \mathbf{a}$ & $\begin{array}{c}3.10\left(\mathrm{~s}, 3 \mathrm{H}, \mathrm{ac} \mathrm{CH}_{3}\right), 7.30(\mathrm{~m}, 1 \mathrm{H}, \mathrm{ph}), 7.50(\mathrm{~m}, 2 \mathrm{H}, \mathrm{ph}) \\
8.05(\mathrm{~m}, 2 \mathrm{H}, \mathrm{ph}), 8.20(\mathrm{~d}, 1 \mathrm{H}, J 8.0 \mathrm{~Hz}, \mathrm{th}) \\
8.40(\mathrm{~d}, 1 \mathrm{H}, J 8.0 \mathrm{~Hz}, \mathrm{th}), 9.25(\mathrm{~s}, 1 \mathrm{H}, \mathrm{ac} \mathrm{NH})\end{array}$ & $\begin{array}{c}3442(\mathrm{ac} \mathrm{NH}), 3184,3082(\mathrm{Ar} \mathrm{C}-\mathrm{H}), 2844(\mathrm{Al} \mathrm{C}-\mathrm{H}), \\
1720(\text { ac C}=\mathrm{O}), 1664(\mathrm{k} \mathrm{C}=\mathrm{O}), 1621(\mathrm{ac} \mathrm{NH}), 1592, \\
1503(\mathrm{C}=\mathrm{N}, \mathrm{C}=\mathrm{C})\end{array}$ \\
\hline $\mathbf{2 b}$ & $\begin{array}{c}2.80\left(\mathrm{~s}, 3 \mathrm{H}, \text { th } \mathrm{CH}_{3}\right), 3.90\left(\mathrm{~s}, 3 \mathrm{H}, \mathrm{ac} \mathrm{CH}_{3}\right), 7.20(\mathrm{~m}, 2 \mathrm{H}, \mathrm{ph}) \\
7.50(\mathrm{~m}, 2 \mathrm{H}, \mathrm{ph}), 7.80(\mathrm{~s}, 1 \mathrm{H}, \mathrm{ac} \mathrm{NH}), 7.90(\mathrm{~s}, 1 \mathrm{H}, \mathrm{th}) \\
8.05(\mathrm{~d}, 1 \mathrm{H}, J 8.0 \mathrm{~Hz}, \mathrm{ph})\end{array}$ & $\begin{array}{c}3457(\mathrm{ac} \mathrm{NH}), 3082,2928(\mathrm{Ar} \mathrm{C}-\mathrm{H}), 2838(\mathrm{Al} \mathrm{C}-\mathrm{H}), \\
1669(\mathrm{ac} \mathrm{C}=\mathrm{O}), 1638(\mathrm{k} \mathrm{C}=\mathrm{O}), 1604(\mathrm{ac} \mathrm{NH}), 1599,1545, \\
1499(\mathrm{C}=\mathrm{N}, \mathrm{C}=\mathrm{C})\end{array}$ \\
\hline $2 c$ & $\begin{array}{c}3.10\left(\mathrm{~s}, 3 \mathrm{H}, \mathrm{ac} \mathrm{CH}_{3}\right), 6.80-7.80(\mathrm{~s}, \mathrm{~m}, 5 \mathrm{H}, \mathrm{ph}), 8.10(\mathrm{~s}, 1 \mathrm{H}, \mathrm{th}) \\
8.60(\mathrm{~s}, 1 \mathrm{H}, \mathrm{ac} \mathrm{NH}), 14.40(\mathrm{~s}, 1 \mathrm{H}, \text { hyd } \mathrm{NH})\end{array}$ & $\begin{array}{c}3473(\text { ac NH}), 3070(\mathrm{Ar} \mathrm{C}-\mathrm{H}), 2922(\mathrm{Al} \mathrm{C}-\mathrm{H}), 1720(\mathrm{ac} \mathrm{C}=\mathrm{O}), \\
1677(\mathrm{k} \mathrm{C}=\mathrm{O}), 1626(\text { ac NH}), 1580,1503,1470(\mathrm{C}=\mathrm{N}, \mathrm{C}=\mathrm{C})\end{array}$ \\
\hline
\end{tabular}

NMR: nuclear magnetic resonance; DMSO- $d_{6}$ : dimethyl sulfoxide; FTIR: Fourier transform infrared spectroscopy; s: singlet; ph: phenyl; m: multiplet; d: doublet; th: thiazole; hyd: hydrazo; Ar: aromatic; k: keto; Al: aliphatic; ac: acetamido. 


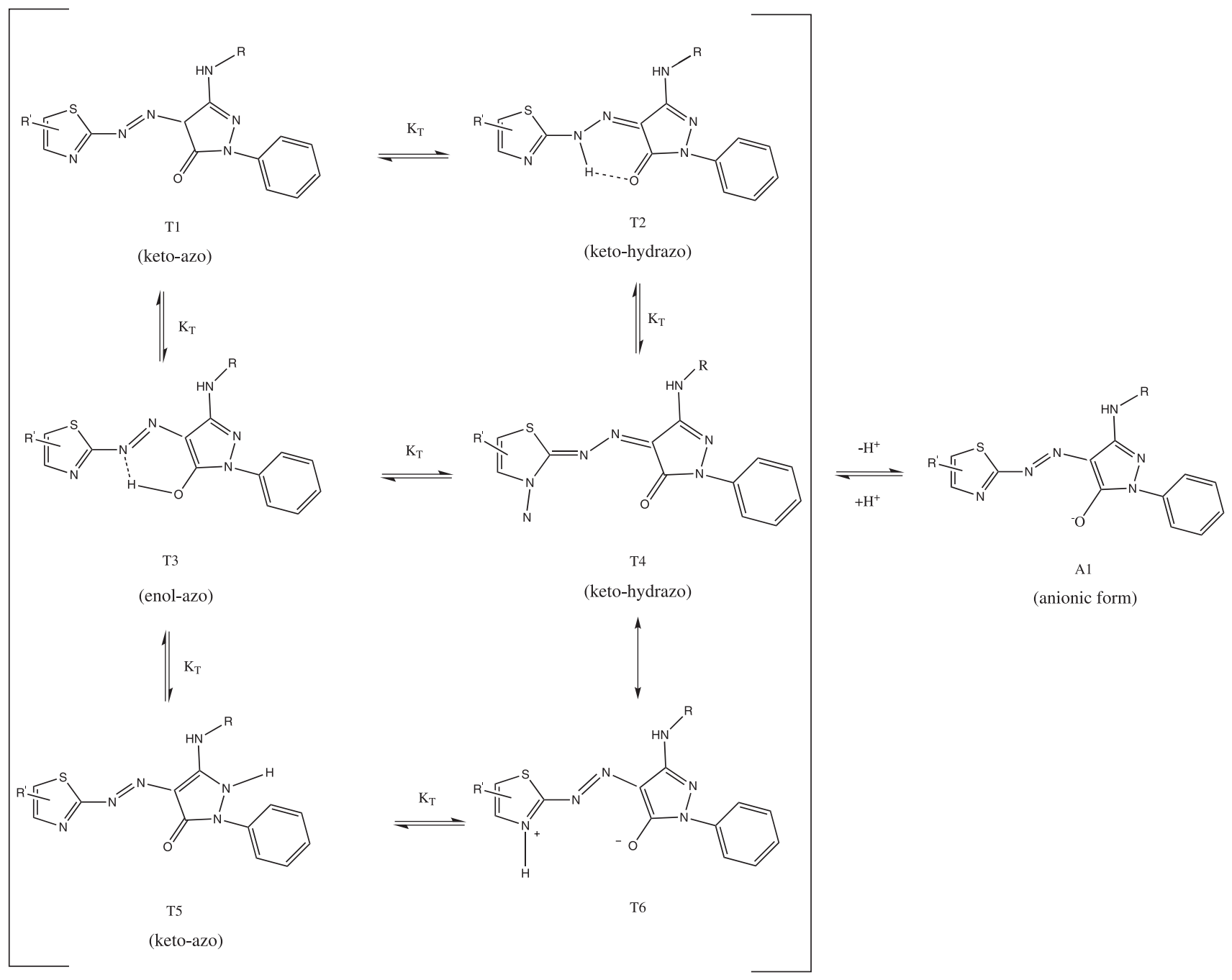

Scheme 3. Tautomeric structures and anionic forms of the dyes (R: $\left.-\mathrm{H},-\mathrm{CO}-\mathrm{CH}_{3}\right)$.

Table 3. $\lambda_{\max }$ values of the dyes

\begin{tabular}{|c|c|c|c|c|c|c|}
\hline & \multicolumn{6}{|c|}{$\lambda_{\max } / \mathrm{nm}$} \\
\hline & $1 \mathrm{a}$ & $1 \mathrm{~b}$ & $1 \mathrm{c}$ & $2 \mathbf{a}$ & $2 b$ & $2 \mathrm{c}$ \\
\hline Chloroform & 394 & 444 & 366,520 & $313,{ }^{a} 480$ & $315,{ }^{\mathrm{a}} 480$ & 324,480 \\
\hline Acetic acid & 388 & 401 & 402 & 480 & 480 & 480 \\
\hline Methanol & $380,{ }^{\mathrm{a}} 424$ & $390,{ }^{a} 439$ & 357,517 & 440 & 443 & 315,463 \\
\hline Acetonitrile & 393 & 410 & 366,534 & 470 & 480 & 324,480 \\
\hline DMF & $390,{ }^{\mathrm{a}} 437$ & $390,{ }^{\text {a }} 443$ & 366,541 & 462 & 480 & 324,470 \\
\hline DMSO & 434 & $390,{ }^{\text {a }} 444$ & 366,540 & 467 & 480 & 324,470 \\
\hline
\end{tabular}

aShoulder. DMF: dimethylformamide, DMSO: dimethyl sulfoxide.

The absorption maximum of dye $\mathbf{1 a}$ reflected bathochromic shift in methanol, DMSO and DMF as compared to the acetic acid, chloroform and acetonitrile. As an example, 1a shows a $\lambda_{\max }$ at 388, 394 and $393 \mathrm{~nm}$ in acetic acid, chloroform and acetonitrile, respectively, those has shifted to 424,434 and $437 \mathrm{~nm}$ in methanol,
DMSO and DMF, respectively (Figure 2) ${ }^{17}$ These results indicate that 1a may be either tautomerizing or ionizing in basic solvents such as methanol, DMSO and DMF. Dye 1b shifted bathochromically in chloroform $\left(\lambda_{\max }\right.$ : $444 \mathrm{~nm})$ besides methanol $\left(\lambda_{\max }: 439 \mathrm{~nm}\right)$, DMSO $\left(\lambda_{\max }\right.$ : $444 \mathrm{~nm})$ and DMF $\left(\lambda_{\max }: 443 \mathrm{~nm}\right){ }^{8}$ The absorbance of 


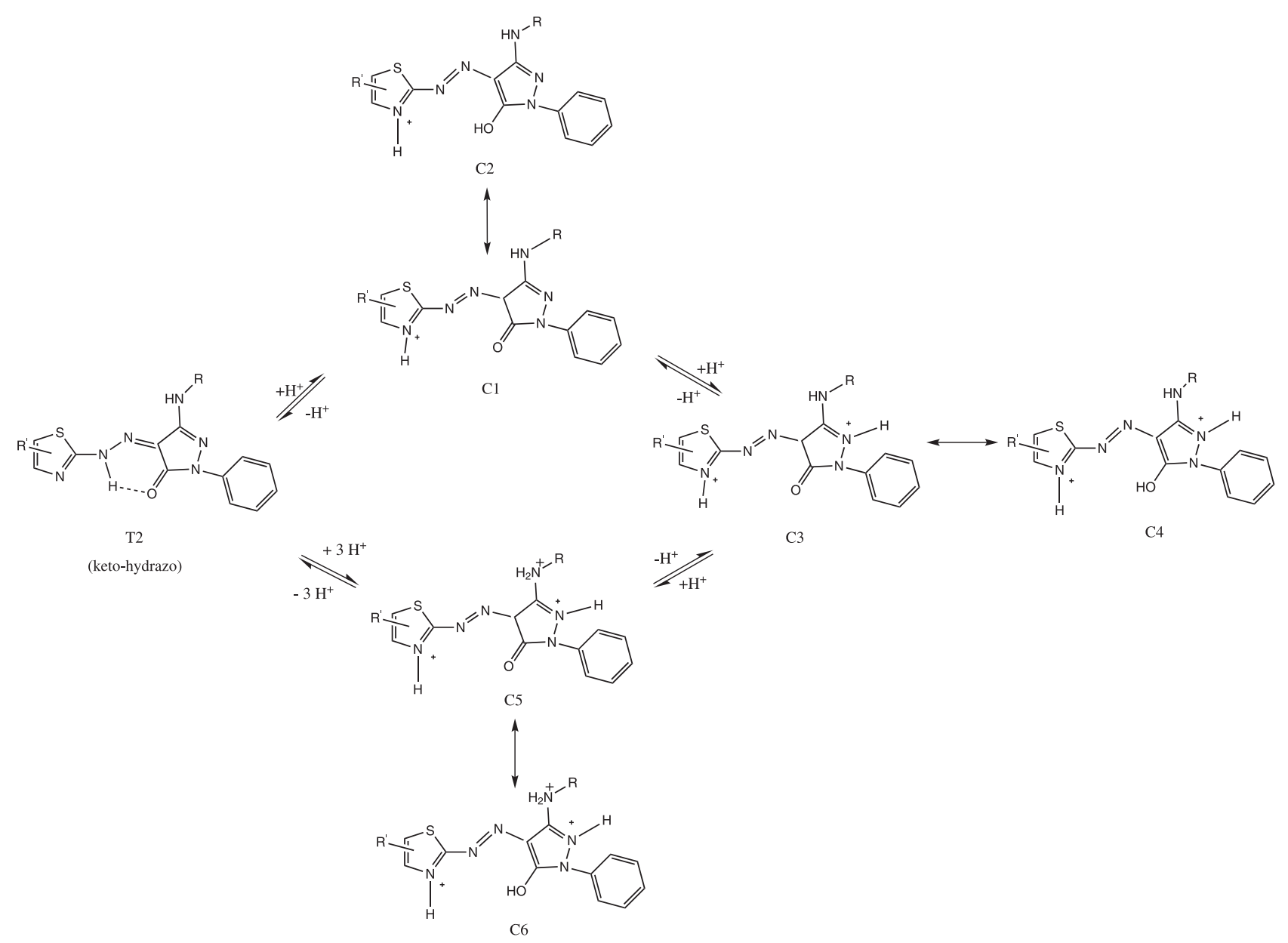

Scheme 4. Possible cationic forms of the dyes $\left(\mathrm{R}:-\mathrm{H},-\mathrm{CO}-\mathrm{CH}_{3}\right)$.

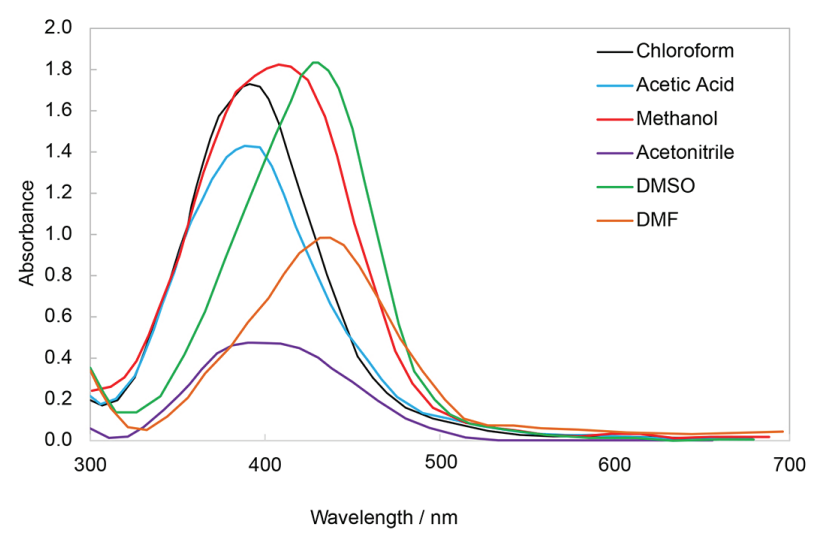

Figure 2. Absorption spectra of dye 1a in various solvents.

dye 1c showed two maxima in all solvents $\left(\lambda_{\max 1}: 357\right.$, $366 \mathrm{~nm}, \lambda_{\max 2}: 517-541 \mathrm{~nm}$ ), except acetic acid. Dye 2a provided bathochromic shift in chloroform, acetic acid, and acetonitrile (480, 480, $470 \mathrm{~nm}$ ), and hypsochromic shift in methanol, DMF and DMSO (440, 462, $467 \mathrm{~nm})$ unlike 1a. The $\lambda_{\max 2}$ of $\mathbf{2} \mathbf{c}$ were similar to that of $\mathbf{2 a}$ in all solvents and $\lambda_{\max 1}$ of $2 \mathbf{c}$ were observed at 315 or $324 \mathrm{~nm}$ in all solvents, except acetic acid. Dye $\mathbf{2 b}$ showed an absorbance at
$480 \mathrm{~nm}$ in chloroform, acetic acid, acetonitrile, DMF and DMSO, whereas the $\lambda_{\max }$ value was changed to $443 \mathrm{~nm}$ in methanol. These findings indicate a $43 \mathrm{~nm}$ difference in the absorbance from DMF towards chloroform (dye 1a).

These results reflect that the absorption behaviors of the synthesized dyes are not related to the polarity of solvents but instead to the proton-donor and acceptor properties of solvents, ${ }^{41}$ which reinforces the ionization rather than tautomerism. To confirm this thesis, the effect of acid and base was also investigated on the absorbance. Absorbances of the synthesized dye solutions in methanol $(\mathrm{HCl}$ and $\mathrm{KOH}$ ) and chloroform (trifloroacetic acid (TFAA) and piperidine) are provided in Table 4.

The absorbance peaks of 1a-1c were more sensitive to acid in both chloroform and methanol. As an example, $\lambda_{\max }$ of $\mathbf{1 a}$ shifted +55 and $+23 \mathrm{~nm}$ in chloroform + TFAA and methanol $+\mathrm{HCI}$, respectively, while it shifted +49 and $+10 \mathrm{~nm}$ in chloroform + piperidine and methanol $+\mathrm{KOH}$, respectively (Figure 3). Absorbances of $\mathbf{1 b}$ and $\mathbf{1 c}$ changed insignificantly when basic solution was added to their solutions in both chloroform and methanol as compared to 1a. Dye 1b displayed slight bathochromic shifts in the $\lambda_{\max }$, i.e., +4 and 
Table 4. $\lambda_{\max }$ values of dyes in acidic and basic solutions

\begin{tabular}{|c|c|c|c|c|c|c|}
\hline \multirow{2}{*}{ Dye } & \multicolumn{6}{|c|}{$\lambda_{\max } / \mathrm{nm}$} \\
\hline & $\mathrm{CHCl}_{3}$ & $\mathrm{CHCl}_{3}+$ TFAA & $\mathrm{CHCl}_{3}+$ piperidine & Methanol & Methanol + HCI & Methanol $+\mathrm{KOH}$ \\
\hline $1 a$ & 394 & $380,{ }^{a} 449$ & $380,{ }^{a} 443$ & $380,{ }^{\mathrm{a}} 424$ & $380,{ }^{\text {a }} 447$ & $380,{ }^{\text {a }} 434$ \\
\hline $1 b$ & 444 & $390,{ }^{\mathrm{a}} 456$ & $390,{ }^{\text {, }} 448$ & $390,{ }^{\mathrm{a}} 439$ & $390,{ }^{a} 458$ & $390,{ }^{a} 440$ \\
\hline $1 \mathrm{c}$ & 366,520 & $401,472^{\mathrm{a}}$ & 366,524 & 357,517 & $411,470^{\mathrm{a}}$ & 370,518 \\
\hline $2 a$ & 313, a 480 & 395, , 457 & $420,{ }^{\text {a }} 457$ & 440 & $400,{ }^{a} 448$ & $400,{ }^{a} 446$ \\
\hline $2 b$ & 315, a 480 & $395,{ }^{\text {, }} 462$ & $420,{ }^{\mathrm{a}} 462$ & 443 & $400,{ }^{\text {a }} 456$ & $400,{ }^{a} 452$ \\
\hline $2 c$ & 324,480 & 395, , 460 & $420,{ }^{a} 460$ & 315,463 & $400,{ }^{a} 478$ & $400,{ }^{a} 473$ \\
\hline
\end{tabular}

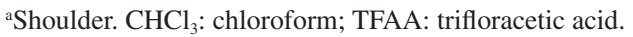
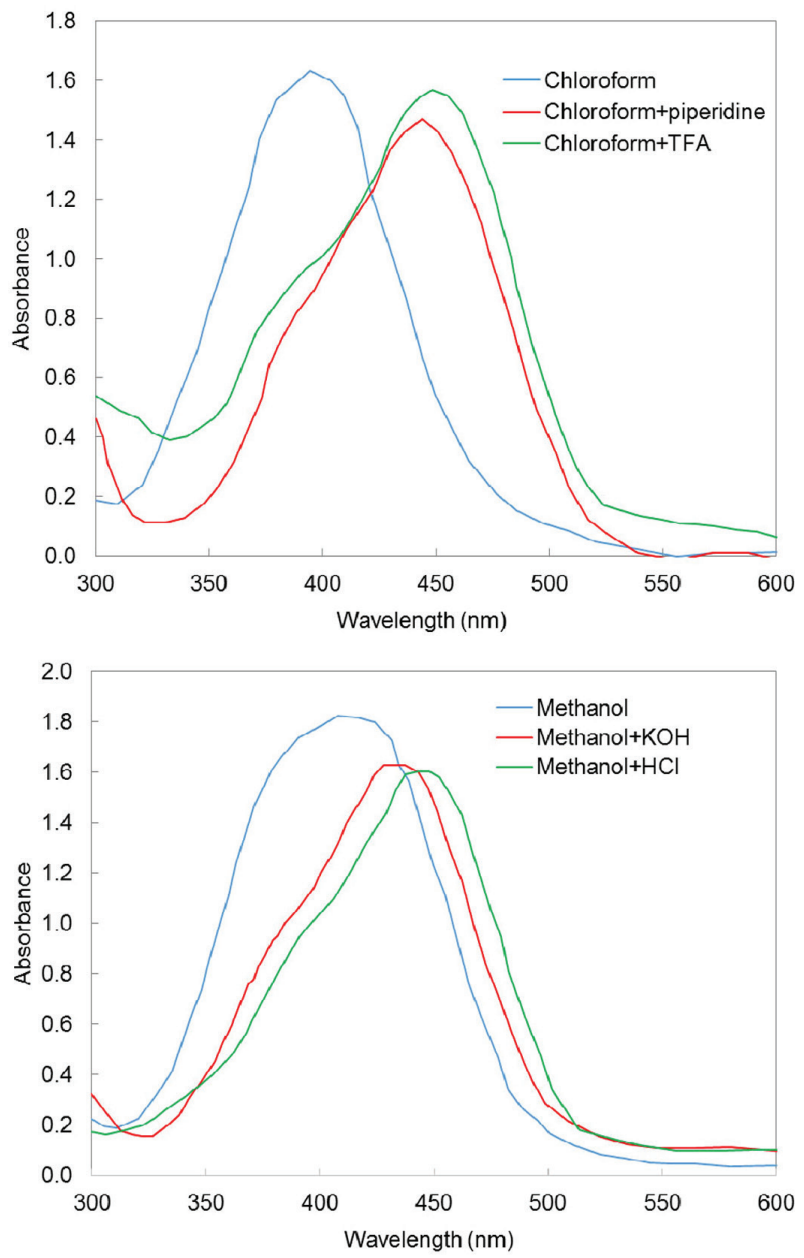

Figure 3. Absorption spectra of dye 1a in acid and base.

$+1 \mathrm{~nm}$ in chloroform + piperidine and methanol $+\mathrm{KOH}$, respectively. Additionally, $\mathbf{1 a}$ and $\mathbf{1 b}$ also showed a shoulder at shorter wavelength (at 380 and $390 \mathrm{~nm}$ ) in all acidic-basic solutions. On the other hand, $1 \mathrm{c}$ shifted +35 and $+54 \mathrm{~nm}$ in chloroform + TFAA and methanol + HCI while it showed a shoulder at 472 and $470 \mathrm{~nm}$, respectively. However, $\lambda_{\max }$ of the same dye did not change significantly upon addition of piperidine to its chloroform solution or addition of $\mathrm{KOH}$ to its methanol solution. These results are similar to the literaure for hetarylazopyrazolones, ${ }^{6,7,17}$ hetarylazocalixarenes, ${ }^{11}$ hetarylazopyridones, ${ }^{3,42}$ hetarylazocoumarines, ${ }^{9}$ hetarylazoquinolines ${ }^{5}$ and hetarylazoindoles. ${ }^{10}$ These results suggest that 1a-1c may be in a mixture of one tautomeric and cationic form in acidic solutions, while they may be in a mixture of one tautomeric and anionic form $\left(\mathrm{A}_{1}\right)$ in basic solutions. ${ }^{8,10}$

Dyes 2a-2c showed similar hypsochromic shift $(-23 \mathrm{~nm}$ for $\mathbf{2 a},-18 \mathrm{~nm}$ for $\mathbf{2 b},-20 \mathrm{~nm}$ for $\mathbf{2 c})$ with shoulders at 395 and $420 \mathrm{~nm}$ in chloroform + TFAA and chloroform + piperidine, respectively. These values sugget that 2a-2c may be in a mixture of two tautomeric form in both chlorofom solutions. By contrast, the $\lambda_{\max }$ of $\mathbf{2 a - 2 c}$ reflected slight bathochromic shift after the addition of $\mathrm{HCI}$ or $\mathrm{KOH}$ to their methanol solutions $(+8,+6 \mathrm{~nm}$ for $\mathbf{2 a}$, $+13,+9 \mathrm{~nm}$ for $\mathbf{2 b},+15,+10 \mathrm{~nm}$ for $\mathbf{2} \mathbf{c}$ in acidic and basic solutions). Dyes 2a-2c showed a shoulder at $400 \mathrm{~nm}$ in both acidic and basic methanol. Thus, these dyes may be in a mixture of tautomeric and cationic form in methanol + HCI, while they may be in a mixture of tautomeric and anionic form $\left(\mathrm{A}_{1}\right)$ in methanol $+\mathrm{KOH} .^{8,10}$

Absorbances of all the examined dyes in acidic and basic solutions are listed in Table 4, while Table 5 contains the effects of dye concentration and temperature on the absorbance. Results showed that absorbances changed insignificantly with concentration and temperature.

\section{Substituent effects}

Absorbance maxima of $\mathbf{1 b}\left(-\mathrm{CH}_{3}\right.$ on thiazole ring at 4-position) shifted bathochromically in acetic acid, methanol, acetonitrile, DMF and DMSO (6-17 nm) relative to 1a. ${ }^{6,7,8,10,17}$ This slight change resulted from weak electron donating effect of $-\mathrm{CH}_{3}$. Highest effect of $-\mathrm{CH}_{3}$ was observed in least polar solvent, i.e., chloroform $(+50 \mathrm{~nm}) .{ }^{17}$ On the other hand, $\mathbf{1 c}\left(-\mathrm{NO}_{2}\right.$ group on thiazole ring at 5-position) reflected both hypsochromic and bathochromical shifts in all solvents except acetic acid. The strong electron-accepting substituent $\left(-\mathrm{NO}_{2}\right.$ 
Table 5. $\lambda_{\max }$ values of the dyes in acidic and basic solution

\begin{tabular}{|c|c|c|c|c|c|c|c|c|c|c|c|c|c|}
\hline \multirow{3}{*}{ Dye } & \multicolumn{13}{|c|}{$\lambda_{\max } / \mathrm{nm}$} \\
\hline & \multicolumn{2}{|c|}{$\operatorname{DMSO}\left(25^{\circ} \mathrm{C}\right)$} & \multicolumn{2}{|c|}{$\operatorname{DMF}\left(25^{\circ} \mathrm{C}\right)$} & \multirow{2}{*}{$\begin{array}{c}\text { DMF } \\
\left(80^{\circ} \mathrm{C}\right)\end{array}$} & \multicolumn{2}{|c|}{ Acetonitrile $\left(25^{\circ} \mathrm{C}\right)$} & \multicolumn{2}{|c|}{ Methanol $\left(25^{\circ} \mathrm{C}\right)$} & \multicolumn{2}{|c|}{ Acetic acid $\left(25^{\circ} \mathrm{C}\right)$} & \multicolumn{2}{|c|}{ Chloroform $\left(25^{\circ} \mathrm{C}\right)$} \\
\hline & Concd. & Dilute & Concd. & Dilute & & Concd. & Dilute & Concd. & Dilute & Concd. & Dilute & Concd. & Dilute \\
\hline $1 \mathbf{a}$ & 434 & 434 & $390,{ }^{\mathrm{a}} 438$ & $390,{ }^{\mathrm{a}} 437$ & $380,{ }^{a} 438$ & 393 & 393 & $380,{ }^{\mathrm{a}} 424$ & $380,{ }^{\mathrm{a}} 424$ & 389 & 388 & 396 & 394 \\
\hline $1 \mathrm{~b}$ & $390,{ }^{\mathrm{a}} 444$ & $390,{ }^{\mathrm{a}} 444$ & $390,{ }^{\mathrm{a}} 443$ & $390,{ }^{\mathrm{a}} 443$ & $390,{ }^{\text {a }} 444$ & 416 & 410 & $390,{ }^{\mathrm{a}} 437$ & $390,{ }^{\mathrm{a}} 439$ & 400 & 401 & 444 & 444 \\
\hline 1c & 366,540 & 366,540 & 366,541 & 366,541 & 366,537 & 366,533 & 366,534 & 357,517 & 357,517 & 402 & 402 & 366,520 & 366,520 \\
\hline $2 a$ & 467 & 467 & 462 & 462 & 462 & 470 & 470 & 440 & 440 & 480 & 480 & $313,{ }^{\mathrm{a}} 486$ & $313,{ }^{\mathrm{a}} 480$ \\
\hline $2 b$ & 480 & 480 & 480 & 480 & 480 & 480 & 480 & 439 & 443 & 480 & 480 & $315,{ }^{a} 487$ & $310,{ }^{\mathrm{a}} 480$ \\
\hline $2 c$ & 324,470 & 324,470 & 324,470 & 324,470 & 324,470 & 324,480 & 324,480 & 315,461 & 315,463 & 480 & 480 & 320,480 & 324,480 \\
\hline
\end{tabular}

ashoulder. DMSO: dimethyl sulfoxide; DMF: dimethylformamide; Concd.: concentrated.

on thiazole ring of diazo component) showed the highest bathochromical shift in acetonitrile $(+141 \mathrm{~nm})$; probably due to resonance stability of the aromatic system. ${ }^{43}$

The $\lambda_{\max }$ of $\mathbf{2 b}$ and $\mathbf{2} \mathbf{c}$ did not change in chloroform and acetic acid as compared to $\mathbf{2 a}$. The $\lambda_{\max }$ of $\mathbf{2 b}$ and $\mathbf{2 c}$ changed as follows: $+3,+20 \mathrm{~nm}$ in methanol, $+10,+10 \mathrm{~nm}$ in acetonitrile, $+18,+8 \mathrm{~nm}$ in DMF, and $+13,+3 \mathrm{~nm}$ in DMSO, respectively. Additionally, dye 2c showed a second peak at 315 or $324 \mathrm{~nm}$ in all solvents, except acetic acid. These data indicate that $\mathbf{2 a - 2 c}$, which were obtained by the acetylation of $\mathbf{1 a - 1 c}$, are less sensitive to effect of substituent on diazo component from 1a-1c. This conclusion may be related to the weak electrondonating ability of acetylamido group $\left(-\mathrm{NH}-\mathrm{CO}-\mathrm{CH}_{3}\right.$; chromophore group) than amino group $\left(-\mathrm{NH}_{2}\right.$; auxochrome group). Acetylation of amino group on coupling component was more effective on the absorbance of $\mathbf{1 a}-\mathbf{1} \mathbf{c}$ from $-\mathrm{CH}_{3}$ substituent on diazo component. The largest change in the $\lambda_{\max }$ was reflected by $\mathbf{2 a - 2} \mathbf{c}$ in acetic acid as compared to 1a-1c. The $\lambda_{\max }$ values of 1a-1c in acetic acid are: 388,401 , and $402 \mathrm{~nm}$, whereas $\mathbf{2 a - 2 c}$ absorbed at $480 \mathrm{~nm}$ in the same solvent. In other solvents, the absorbances of $\mathbf{2 a}$ and $\mathbf{2 b}$ shifted bathocromically in respect to their corresponding dyes 1a and 1b. The shoulders at 380, 390 (in methanol, DMF) (1a) and $390 \mathrm{~nm}$ (in methanol, DMF, DMSO) (1b) disappeared while new shoulders appeared at 313 (2a) and $315 \mathrm{~nm}(\mathbf{2 b})$ in chloroform. On the other hand, $\lambda_{\max }$ values of $\mathbf{2 c}$ showed larger hypsochromical shifts in all solvents as compared to their corresponding dye 1c.

\section{Fastness properties of dyes}

The colors of dyes on polyester fabric are shown in Figure 4.

\section{Light fastness}

The synthesized dyes showed high light fastness performance on polyester fabric (Table 6). The light fastness levels of dyes $\mathbf{2 a}$ and $\mathbf{2 c}(5,3 / 4)$ were smaller than their corresponding dyes $\mathbf{1 a}$ and $\mathbf{1 c}(6,3 / 4-4)$, however, $\mathbf{1 b}$ and $\mathbf{2 b}$ were similar (5). Thus, the highest light fastness level was found as 6 for dye 1a, while the least was $3 / 4$ for dye $\mathbf{2 c}$.

\section{Rubbing fastness}

Dyed polyester fabrics (Figure 4) displayed notable dry and wet rub fastness results (Table 6). The highest dry and wet rub fastness value was 5 for $\mathbf{1 a}$ and $\mathbf{1 b}$, while the least dry and wet rub fastness was 3 for dye $\mathbf{2 c}$. The dry rub fastness values of $\mathbf{1 c}, \mathbf{2} \mathbf{a}$ and $\mathbf{2} \mathbf{b}(4,5,4 / 5)$ were slightly higher than the wet rub fastness values of same dyes $(3 / 4,4,4)$. In addition, the rub fastness values of 2a-2c (3-acetamidopyrazolone derivatives) in both wet and dry tests were slightly lower than their corresponding dyes 1a-1c (3-aminopyrazolone derivatives) except the dry rub fastness of $\mathbf{2 a}$. The wet and dry rub fastness of the dyes 1a-1c were 5-5, 5-5, (3/4)-4, dyes 2a-2c showed

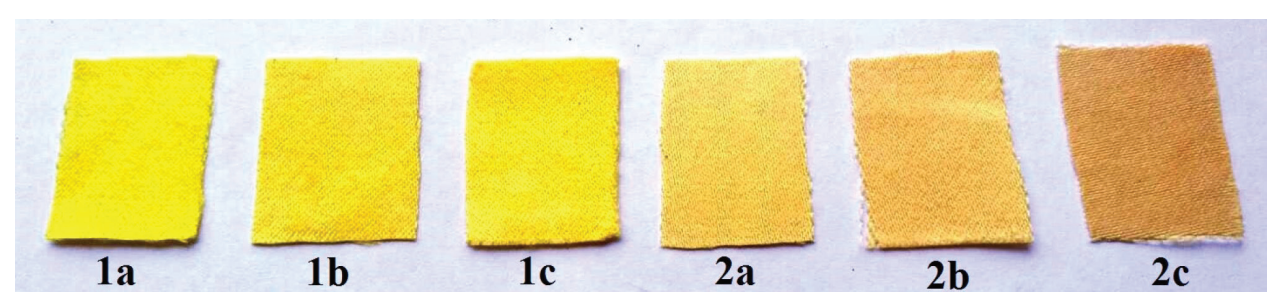

Figure 4. Colors of dyes on polyester fabric. 
Table 6. Light and rubbing fastness values of the synthesized dyes

\begin{tabular}{lcccc}
\hline & & Light fastness & \multicolumn{2}{c}{$\begin{array}{c}\text { Rubbing fastness (cotton staining) } \\
\text { (ISO 105-X12) }\end{array}$} \\
\cline { 3 - 4 } Dye & Color of dye on polyester fabric & Wet & Dry \\
\hline 1a & yellow & (ISO 105-B04) & 5 & 5 \\
1b & yellow & 6 & 5 & 5 \\
1c & yellow & 5 & $3 / 4$ & 5 \\
2a & yellow/orange & $3 / 4-4$ & 4 & 4 \\
2b & yellow/orange & 5 & 4 & 3 \\
2c & orange/brown & 5 & 3 & $4 / 5$ \\
\hline
\end{tabular}

Table 7. Washing fastness values of the synthesized dyes

\begin{tabular}{|c|c|c|c|c|c|c|c|}
\hline \multirow{2}{*}{ Dye } & \multirow{2}{*}{ Shade change } & \multicolumn{6}{|c|}{ Multifiber staining (ISO 105:C06) } \\
\hline & & Acetate & Cotton & Nylon 6.6 & Polyester & Acrylic & Wool \\
\hline 1a & 5 & 5 & 5 & $4 / 5$ & 5 & 5 & $4 / 5$ \\
\hline $1 b$ & 5 & 5 & 5 & 5 & 5 & 5 & 5 \\
\hline 1c & 4 & 4 & $3 / 4$ & 4 & 4 & $3 / 4$ & 4 \\
\hline $2 \mathbf{a}$ & $4 / 5$ & $4 / 5$ & 5 & 4 & $4 / 5$ & 5 & 4 \\
\hline $2 b$ & $4 / 5$ & 4 & 5 & $4 / 5$ & 4 & $4 / 5$ & 4 \\
\hline $2 \mathrm{c}$ & $3 / 4$ & 3 & $3 / 4$ & 3 & 3 & $3 / 4$ & 3 \\
\hline
\end{tabular}

4-5, 4-(4/5), 3-3, respectively. On the other hand, dry rub fastness of $\mathbf{1 a}$ and $\mathbf{2 a}$ was found as $5 . .^{32,33}$

Washing fastness

The washing fastness shade change values of dyed fibers are commercially acceptable. Especially dyes $\mathbf{1 a}, \mathbf{1 b}, \mathbf{2 a}$, 2b exhibited excellent shade change levels (4/5-5) and excellent staining levels (4-5) (Table 7). The best staining levels were found as (4/5)-5 for dyes $\mathbf{1 a}$ and $\mathbf{1 b}$, whereas the least were provided by (3/4)-4 for $\mathbf{1 c}$ and 3-3/4 for dye $\mathbf{2 c}$. The washing fastness values of the dyed polyester fabrics are given in Table 7.

Fastness tests results of polyester fabrics dyed with $\mathbf{1 a - 1 c}$ (3-aminopyrazolone derivatives) were generally higher than those of $\mathbf{2 a - 2 c}$ (3-acetamidopyrazolone derivatives). This may have occured due to the stronger binding of amino group $\left(-\mathrm{NH}_{2}\right)$ with polyester fibers as compared to the binding of acetamido group (-NH-CO- $\left.\mathrm{CH}_{3}\right)$.

\section{Conclusions}

Two series of amino- and acetamido-based monoazo dyes were synthesized from 1-phenyl-3-aminopyrazol-5-on and forwarded to their characterization, UV absorption, tautomeric forms and fastness properties. Variation in the absorbance of the synthesized dyes in acidic and basic media showed that they were more sensitive towards acids. The dyes generally demonstrated bathocromic shifts in polar solvents. Nitro-substituted dye (1c) showed the highest bathochromic shift in DMSO and DMF. $\lambda_{\max }$ values of the dyes $\mathbf{2 a - 2} \mathbf{c}$ either did not change or changed slightly while the dyes 1a-1c were more sensitive to effect of substituent. In adition, keto-hydrazone $\left(\mathrm{T}_{2}\right)$ tautomer of all dyes predominantly existed in both solid state and in solution. The colors of the dyes $\mathbf{2 a - 2 c}\left(-\mathrm{NH}-\mathrm{CO}-\mathrm{CH}_{3}\right.$; chromophor) on polyester fabric were darker than colors of dyes 1a-1c (- $\mathrm{NH}_{2}$; oxochrome). This may have occured due to the absorbances of $\mathbf{2 a - 2} \mathbf{c}$ were more bathocromic in respect to their corresponding dyes 1a-1c. Fastness values of the synthesized dyes on polyester fabric demonstrated that the binding of amino group $\left(-\mathrm{NH}_{2}\right)$ with polyester fibers is stronger than binding of acetilamido group $\left(-\mathrm{NH}-\mathrm{CO}-\mathrm{CH}_{3}\right)$. Fastness tests as a whole were satisfactory in comparision with the literature. We suggest to use these compounds in the dye/color industry and to explore their physicochemical and biological properties.

\section{Supplementary Information}

Supplementary data are available free of charge at http://jbcs.sbq.org.br as PDF file. 


\section{References}

1. Metwally, M. A.; Khalifa, M. E.; Amer, F. A.; Dyes Pigm. 2008, 76, 379 .

2. Song, H.; Chen, K.; Tian, H.; Dyes Pigm. 2002, 53, 257.

3. Ertan, N.; Eyduran, F.; Dyes Pigm. 1995, 27, 313.

4. Masoud, M. S.; Mohamed, G. B.; Abdul-Razek, Y. H.; Khalil, A. E.; Khairy, F. N.; Spectrosc. Lett. 2002, 35, 377.

5. Saylam, A.; Seferoğlu, Z.; Ertan, N.; Dyes Pigm. 2008, 76, 470.

6. Ertan, N.; Dyes Pigm. 2000, 44, 41.

7. Karc1, F.; Ertan, N.; Dyes Pigm. 2002, 55, 99.

8. Karc1, F.; Karc1, F.; Dyes Pigm. 2008, 76, 147.

9. Karc1, F.; Ertan, N.; Color. Technol. 2005, 121, 153.

10. Seferoğlu, Z.; Ertan, N.; Russ. J. Org. Chem. 2007, 43, 1035.

11. Sener, I.; Karc1, F.; Kılıc, E.; Deligoz, H.; Dyes Pigm. 2004, 62, 141.

12. Emandi, A.; Serban, I.; Bandula, R.; Dyes Pigm. 1999, 41, 63.

13. El-Borai, M. A.; Rizk, H. F.; El-Hefnawy, G. B.; Ibrahim, S. A.; Aser, S. S.; El-Sayed, H. F.; Fibers Polym. 2016, 17, 729.

14. Abdel, M. A. M. E.; Fathy, A.; Amer, G. A. M.; Dyes Pigm. 2012, 92, 902.

15. Sabnis, R. W.; Rangnekar, D. W.; Dyes Pigm. 1989, 10, 295.

16. Ho, Y. W.; Dyes Pigm. 2005, 64, 223.

17. Aktan, E.; Ertan, N.; Uyar, T.; J. Mol. Struct. 2014, 1060, 215.

18. Matsuoka, M.; Infrared Absorbing Dyes, vol. 1, $4^{\text {th }}$ ed.; Plenum Press: New York and London, UK, 1990.

19. Matsuoka, M.; J. Soc. Dyers Colour. 1989, 105, 167.

20. Bach, H.; Anderle, K.; Fuhrmann, T.; Wendorff, J. H.; J. Phys. Chem. 1996, 100, 4135.

21. Sing, S. P.; Heterocycles 1990, 31, 855.

22. Küçükgüzel, S. G.; Rollas, S.; Erdeniz, H.; Kiraz, M.; Ekinci, A. C.; Vidin, A.; Prog. Drug Res. 2000, 35, 761.

23. Baumann, M.; Baxendale, R.; Ley, S. V.; Nikbin, N.; Beilstein J. Org. Chem. 2011, 7, 442.

24. Baumann, M.; Baxendale, R.; Beilstein J. Org. Chem. 2013, 9 , 2265.

25. Rizk, H. F.; Ibrahim, S. A.; El-Borai, M. A.; Arabian J. Chem. 2017, 10, 3303.

26. Zollinger, H.; Color Chemistry: Synthesis, Properties and Applicatios of Organic Dyes and Pigments, $3^{\text {rd }}$ ed.; Wiley-VCH: Zürich, Switzerland, 2003.
27. Hunger, K.; Industrial Dyes Chemistry, Properties and Applications; Wiley-VCH: Weinheim, Germany, 2003, p. 14.

28. Graham, B.; Porter, H. D.; Weissberger, A.; J. Am. Chem. Soc. 1949, 71, 983.

29. ISO 105-B04: Textiles - Tests for Colour Fastness - Part B04: Colour Fastness to Artificial Weathering: Xenon Arc Fading Lamp Test; International Organization for Standardization: Geneve, 1994.

30. ISO 105-C06: Textiles - Tests for Colour Fastness - Part C06: Colour Fastness to Domestic and Commercial Laundering; International Organization for Standardization: Geneve, 2010.

31. ISO 105-X12: Textiles - Tests for Colour Fastness - Part X12: Colour Fastness to Rubbing; International Organization for Standardization: Geneve, 2016.

32. Standard Methods for the Determination of the Color Fastness of Textiles and Leather, $5^{\text {th }}$ ed.; Society of Dyes and Colorists Publication: Bradford, England, 1990.

33. Bakan, E.; Karc1, F.; Avinc, O.; Fibers Polym. 2018, 19, 670.

34. Snavely, F. A.; Yoder, C. H.; J. Org. Chem. 1968, 33, 513.

35. Zamanloo, M. R.; Shamkhali, A. N.; Alizadeh, M.; Mansoori, Y.; Imanzadeh, G.; Dyes Pigm. 2012, 95, 587.

36. Aktan, E.; Babur, B.; Seferoglu, Z.; Hokelek, T.; Sahin, E.; J. Mol. Struct. 2011, 1002, 113.

37. Aktan, E.; Seferoglu, Z.; Hokelek, T.; Sahin, E.; Color. Technol. 2012, 128, 371.

38. Catıkkas, B.; Aktan, E.; Seferoglu, Z.; Int. J. Quantum Chem. 2013, 113, 683.

39. Seferoğlu, Z.; Yalçın, E.; Babür, B.; Seferoğlu, N.; Hökelek, T.; Yılmaz, E.; Şahin, E.; Spectrochim. Acta, Part A 2013, 11, 314.

40. Karcı, F.; Demircalı, A.; Karcı, F.; Kara, İ.; Ucun, F.; J. Mol. Struct. 2009, 935, 19.

41. Gagnon, E.; Boivin, J. L.; Jones, R. N.; Tetrahedron 1970, 26, 1571.

42. Peng, Q.; Li, M.; Gao, K.; Cheng, L.; Dyes Pigm. 1992, 18, 271.

43. Babür, B.; Ertan, N.; Spectrochim. Acta, Part A 2014, 131, 319.

Submitted: December 26, 2019

Published online: April 14, 2020 